\title{
COMPULSORY STATE INSURANCE OF WORKINGMEN
}

The merits of a teleological institution, such as a system of compulsory State insurance of labor undoubtedly is, must be judged by the degree of its success in accomplishing the results aimed at. A certain agreement as to the final aim is therefore necessary for an intelligent and fruitful discussion of the subject. The purpose of labor insurance is a very definite one. It is not expected to solve the "social problem in its entirety," insofar as this problem embraces the whole question of equitable distribution of wealth and a harmonious development of society towards higher forms of organization. Labor insurance, or rather, insurance of workingmen, is in many respects no different from all the other forms of insurance-it is an effort to substitute a social guarantee against the results of emergencies and accidents for the purely personal responsibility which is still the rule in many countries.

Now, for that very reason, any system of labor insurance is violently objected to by many. If one prefers individual responsibility to a social guarantee, whatever his argument, he will necessarily object most strenuously to a system of compulsory State insurance, for the more complete and efficient the system, the more objectionable will it seem to him. The limits of this paper do not permit an exhaustive discussion of the comparative merits of labor insurance and saving, which is the only alternative of provision against the emergencies of the future. It may briefly be indicated, however, that in no other branch of insurance has the alternative of saving ever been seriously insisted upon. Think what this principle would lead to in the domain of fire, marine or any other form of insurance. The modern business man prefers to insure himself against the effects of a possible burglary, or even against the fluctuation of the markets. This has always been pointed out as evidence of the greatest and most commendable prudence. The increase of frequency of conflagrations or burglaries or shipwrecks, even if it could be easily proven to be the result of them, could never be seriously used as an argument against the various forms of insurance. 
Yet it cannot be denied that the workingman is much more liable to meet with adversity than the comfortable home of a well-todo man is to go up in smoke and flame. Sickness, death, accident, sudden unemployment-all these stare into the face of each and every workingman. Old age, with accompanying incapacity to work, is the inevitable fate of him whose only means of existence is his labor power, and then only if wanted by the employer of labor. To claim that any considerable degree of saving is possible for the mass of the wage workers is to claim that the average wage of an American worker is much too high for the satisfaction of his legitimate immediate wants - an optimistic view of which the most partisan crier for prosperity is but seldom guilty. And even if such saving were possible, where is the guarantee against all these emergencies (sickness, death, accidental injury), if they occur before the necessary savings have been accumulated? It may be well to prepare oneself for the "rainy day," but will the "rainy day" delay its coming until one is prepared?

The claim has recently been made by a trained economist and sociologist, ${ }^{1}$ that saving (i.e., a purely individual guarantee) is a much higher, more efficient and commendable method of gaining the security against possible emergencies, than insurance (i.e., a social guarantee), and that only that form of insurance is commendable which is a modified form of saving. This view is not infrequently met with among American economists, notwithstanding the vast experience of Europe, which all points in the direction of insurance rather than savings. When this European experience is pointed out, the answer is invariably given that, no matter how successful in European countries, with their strongly bureaucratic administrations, State labor insurance is utterly at variance with the individualistic ideals of the American people. Things which are un-American to-day are very apt to become very much American to-morrow, however, as the social history of this country for the last fifty years teaches us, and the extreme individualism of the American people (a purely historic growth which has acquired in the eyes of some the appearance of almost generic immutability) has had its foundation very much weakened of late by the continuous attacks of perceptible social forces. If European experiences and figures can be best used

1 Prof. J. H. Hamilton: "Savings and Saving Institutions." 
to impress the general feasibility, practicability and usefulness of State insurance, American experiences and statistics are perfectly sufficient to break down the defense of inadaptability to local conditions and our national psychology. In the magnificent building for Social Economics at the Louisiana Purchase Exposition may be found a small booth of a purely American insurance company which makes a specialty of insurance of laborers, and only one branch of that - the least important one-insurance against death. The booth is decorated with statistical figures which bear directly upon the problem under discussion. The $13,448,000$ industrial insurance policies which are in force at the present time in the United States(as against $6,667,000$ savings-bank accounts, only a smaller part of which probably belong to the wage-earning class of the country) bear strong evidence that the American wage worker, no less than his European brother, adheres to the principle of insurance and prefers a social guarantee to purely personal responsibility and "self-help."

This bit of social statistics may be used against the plan of well regulated State insurance. It may be claimed, and in fact it has been often claimed, that insofar as there is a demand for labor insurance, it has been or may be supplied by private initiative, and that introduction of the State into this undertaking would be an unnecessary and harmful extension of governmental activity in competition with private enterprise. It devolves upon us, therefore, to determine whether State or private insurance is the better, the more efficient, the more useful plan.

Judged simply by numerical results, the advantages of State insurance can hardly be overestimated. A comparison of German insurance statistics with the meager data obtainable in this country leaves an impression which is hardly in favor of this country. According to the latest data "the following number of working persons have enjoyed the benefits of: $\mathrm{I}$. Sick insurance-3,617,022 sick persons (with $66,65^{2,488}$ sick days) with 163,400 ,000 marks indemnity (sickness, death-money, as well as cost of medical attendance); 2. Accident insurance-585,596 wounded, 12, I 28 married women, 26,612 children, 256 parents (as dependent upon the wounded being cared for in hospitals), 53,48 $\mathrm{I}$ widows, 87,035 children, 3,147 parents

2 Official catalogue of the exhibition of the German Empire at the International Exposition, St. Louis, 1904. P. 342. The English of the original is faithfully followed.

[333] 
(of deceased)-total, 768,255 persons, with 100,000,000 marks indemnity; 3 . Invalid insurance $-549,000$ invalid pensions amounting to $66,300,000$ marks, 203,000 old age pensions amounting to 24,700 ,ooo marks; total number of pensions, 752,000 , amounting to 91,000 ,ooo marks; I 9 I,000 persons with 6,900,000 refunded; 33,000 persons in medical treatment with $7,100,000$ marks, total, 976,000 persons with 105,000,000 marks indemnity."

"From the above statement it will be seen that in one year over five million persons in need of help received about 370,000,000 marks." "Help" is rather an unfortunate word, smacking of charity. Over five million people received a social indemnity for individual accidents and mishaps. What has the United States to show as against this tremendous record?

There are no figures. As was recently shown by the writer elsewhere, ${ }^{3}$ instead of sickness insurance we have medical charity with all its harmful results, instead of accident insurance a series of common law doctrines which make the employer's responsibility for injury almost a myth, and instead of life and death insurance "the tremendous system of exploitation of the poorest and neediest which goes by the name of industrial insurance."

"We have in the United States labor insurance by unions, which are financially weak and in which all the burden falls upon the workers themselves. We have insurance by small private companies whose object is gain, whose financial standing is doubtful, and whose methods are often dishonest because of lack of control. And, finally, we have insurance by employers, which, applying only to a few employees, is probably accounted for in the difference of wages."

Experience, therefore, corroborates the conclusions of a priori reasoning that nothing short of compulsory insurance can make the benefits of insurance universal. A study of European statistics will clearly indicate this deduction-that the less compulsory a system of insurance is, the fewer people partake of its benefits.

Here we have the most powerful argument in favor of a system of compulsory State insurance. The advantages of universal insurance are not only quantitative, in that it bestows the benefits of insurance upon everybody instead of the selected few, but also qualitative, as we shall presently see. Here again a few "first principles"

3 Journal of Political Economy, June, 1904. P. 379. 
must be enunciated. The writer takes the standpoint that it is the condition of employees, and not of American employers, that calls for corrective measures. That, he imagines, is pretty well agreed upon by the modern, progressive American economist. It seems clear, therefore, that the burden of labor insurance must not lie too heavily upon the wage workers of the country. "The escape from future suffering must not, if possible, be provided at the expense of a perceptible reduction of present happiness, of which the average workingman's stock is by no means any too large." An efficient system of labor insurance must not be a burden to the workingman, and from the standpoint of the latter that system will be most efficient, the weight of which will be felt least by him. Socially, the expenses of labor insurance can in no way be considered an element of cost while it represents a legitimate claim upon the value of the product, just as fire or marine insurance does. And if this claim cause a disturbance in the existing process of "normal distribution," it is certainly desirable that this new claim should not be shifted upon the portion the workingman had received. In other words, the "cost" of labor insurance should fall upon the employer. Of course each system of State labor insurance endeavors to meet this just demand by enforcing contributions from the employers. Yet, even if the employer be forced to pay all the expenses of labor insurance (which no system of labor insurance at present requires), will the burden be shifted upon the workingman and react upon his wages if the system should embrace only a portion of the wage earners instead of the whole class; for where the advantages of labor insurance are granted only to a limited group, a certain mobility of labor will act as a ready corrective in adjusting wages. ${ }^{4}$ And universal insurance can only mean compulsory insurance-that is, compulsory by the State. For a system of insurance may come under the definition of "State insurąnce," as, for instance, the case with the German Krankenversicherung, the actual work of which is done by co-operative organization under voluntary control. State insurance need not necessarily mean that the actual work of detail be done by bureaucratic organization. The compulsion, regulation and control are the necessary factors.

To quote again from a previous study, "Proceeding from the

1 For a fuller discussion of what the writer has called "the incidence of labor insurance" see the article quoted in the Journal of Political Economy.

[335] 
assumption that the incidence upon profits is the more desirable one, we see that such incidence is less open to question where the employer pays the preminm rather than the employee." The necessity for such contribution is hardly questioned by this time in Germany. In America the fear of such contributions is the prime force of the opposition to any system of labor insurance. Yet, if labor insurance be intended to do away with degrading medical charity, with tedious damage suits, and with poor-and workhouses, the justice of such contributions from the industry and assistance from the State will appear as self-evident and legitimate as is at present the appropriation for charities and corrections. Any equitable distribution of the expenses of insurance, based either upon the paying ability or the responsibility for diseases, accidents, invalidity and fatalities, must include the employer. This can be accomplished only through some system of State insurance.

Moreover, if some system of universal labor insurance be acknowledged necessary, it can easily be shown that State insurance is the cheapest and most economical system in comparison with the results accomplished. Not only can a system of collection of contributions be best organized and cheapest, but a great many other economies may be introduced. Private insurance is a business, and as well as any other business exists for profit. But any justification for profit is here utterly lacking. The business of insurance is not a productive business; it is simply a process of distribution. The highest business genius, the best management cannot add any increment of value, no matter what theory of value we advocate. As a machine for the transformation of heat into active energy is judged by the percentage of loss of energy, so an insurance organization must be judged by the relation of its business expenses and profits to the sum total of money received. The only virtue, the only social service private insurance business can lay claim to is the process of "soliciting business," of spreading the advantages over larger and larger areas; but that can be done at one stroke by a legislative enactment. As a basis of comparison between the expenses of State and private insurance we have our American system of "industrial insurance" as against the German system. Now, it is a well-known fact that the very process of collection, the moving of premiums from the pockets of the insured into the general treasury consumes from 20 to 25 per [336] 
cent. of the premiums. ${ }^{5}$ This does not take into consideration the enormous expenses of the vast administrative machinery, central as well as local, salaries, rent, etc. With the high commission the agents are a set of miserably underpaid fellows, for a needlessly large force of agents is kept, in order to stimulate them towards writing "new business," on which the commission is very high. The work of collection scarcely demands more than two days' work through the week, so that the rest of the time may be devoted to soliciting. In other words, it is not a fair claim that the nature of the business and the character of the insured necessitate this high expense; it is not the material that causes so much friction, but the very organization of the machine, constructed with the view of increasing the business. The intelligent business or professional man, who gets the insurance policy under the very best conditions, to whom insurance is often a most profitable investment, has no conception of the peculiar conditions of an industrial insurance policy.

Our case for compulsory State insurance may be summed up in the following few statements:

I. The economic condition of the wage earner is such as to provide no guarantee against poverty and destitution in case of injury, sickness, or loss of work.

2. Individual saving cannot be relied upon to correct this evil, and some sort of insurance becomes necessary.

3. Unless insurance be universal it will react heavily upon the finances of the workingman.

4. To be universal the system of insurance must be enforced and controlled by the State; that is, it must be a system of compulsory State insurance.

5. A well regulated system of State insurance must be more economical and efficient than private insurance systems.

As against these advantages many arguments are brought against State insurance of labor, both from theoretical considerations as well as from the practical study of the insurance results. It will be worth while to examine these arguments.

It may be said that ( $\mathrm{I}$ ) labor insurance represents an unwarranted

6 The collecting agent usually receives 15 per cent., or even 20 per cent: The ability of investing the funds is here not taken into consideration, for it is of importance only in the "ordinary" branch of insurance, which approaches saving and is not available to the wage worker. 
interference of the State with private industry, with the relations of capital and labor; (2) that it is an effort to abrogate the personal liberty of the employer and employee; (3) that its object is to create an unfair competition to the business of private insurance; and (4) that it is tantamount to a process of confiscation from the employer to the employee, and is, therefore, an obnoxious piece of class legislation. It is this line of argument that is made use of in the effort to show how perfectly un-American a system of "compulsory State insurance" would be.

Our views of the legitimate functions of government are undergoing very rapid changes just now. Beginning with the protective tariff and leading up to the "Oleomargarine law" and the efforts to pass the Merchant Marine Subsidy Act, the American State has often influenced conditions of private business. A system of well regulated sickness and accident insurance is no more an infringement upon personal liberty than an efficient employers' liability act would be; in fact, it is but a modified system of employers' liability, more efficient and less troublesome. And if it create a competition to private insurance, this competition would be an excellent test to determine how far this business of insurance is economically legitimate; i. e., how far its profits are economically defensible, for a system of State insurance would not eo ipso destroy the private business. The economist has heard quite enough of this argument, we imagine, in connection with the projects of parcels post, postal savings banks, and the government ownership of telegraphsi And as to the personal liberty of the employee, we might place against it the interests and rights of the helpless wife and children, who are often left without the slightest provision for the immediate future. In short, we still have to hear of an argument which would represent anything more than the natural inertia against any departure from the old, complacent practice of non-interference.

An exception must surely be made in favor of the argument of excessive cost to the employers. Here we have a real social force whose opposition to an important social measure is at least well defined and easily understood.

In an extensive criticism of the German labor insurance law an American writer emphasizes this point: "The general effect of the

- Henry W. Farnam, "The Psychology of German Workingmen's Insurance," Yale Reviaw, May, 1904 . 
insurance law has been to permanently turn a certain stream of income from the pockets of the taxpayers and employers into the pockets of the wage receivers." The force of this statement as an argument against labor insurance will not appear self-evident to everybody, however. For it has truly been said ${ }^{7}$ that if compulsory labor insurance influences wages in the broad sense of the word, $i . e$., influences the true returns to the laborers for his work-it is no different from the legislative regulation of the hours of labor, of sweating, child labor, etc. If the point be that wages have been influenced in the undesirable direction, it has to be shown that the wages in Germany are too high and the profits too low; that Germany is losing its hold on the international market. Whoever makes an effort to prove all that will have quite a difficult task on his hands. If the economic effects of labor insurance be such as this criticism indicates, one of the most serious economic objections to the system is thus removed; viz: that the cost of insurance, being an element in the cost of production, will be reflected in the price of the goods and thus the workingmen, as consumers, will return what gain they obtained as producers.

The author quoted, however, finds in the working system a series of highly harmful psychological effects. "Compulsory insurance has not filled the working classes with gratitude toward the government, since it was avowedly a measure aimed at the Social Democratic party and, therefore, regarded with suspicion, nor has it made the workingmen friendly and conciliatory toward the employers, since the burden of insurance is borne involuntarily by the latter. On the other hand, the effect of giving them allowances and help in time of trouble has apparently been to weaken the spirit of self-help, to increase the demands upon the public purse, and to make them less wise and responsible in their expenditure."

Surely the claims of novelty cannot be made in favor of these arguments. They are interesting, nevertheless, in showing that opposition to compulsory State insurance soon reduces itself to opposition to the very principle of labor insurance, with the wise pointing at savings as the real method. Yet no effort has ever been made to show that the system of private saving could accomplish those enormous economic and social results which labor insurance

7 Norbert Pinkus, "Workmen's Insurance in Germany." Yale Review, May, 1904. 
evidently does. Opponents of labor insurance have not tired of putting forth that argument of increased carelessness, of the practice of deception for the last thirty years. It seems that by a process of natural selection this argument has survived all these years as the most weighty one, but the statistical basis of this claim will not stand the most superficial analysis. Where dozens of causes and factors have combined to increase the frequency of accidents, it is extremely hazardous to put forth the system of labor insurance as the only real factor. As well might we say that increase in ordinary life insurance is the cause of the growing number of suicides, and rail against life insurance; as well might we say that fire insurance has caused the Chicago, the Baltimore, and the East River horrors, and loudly advocate the abolition of fire insurance. Statistical evidence which is usually brought in support of this view shows nothing beside the mere fact that since the introduction of labor insurance in Germany-i. e., during the last two decades-the number of accidents reported has increased. No more glaring example of the old fallacy, "Post hoc, ergo propter hoc," could be committed. The claim that labor insurance has been the main cause of the growth of German industry, of German exports, and of half a dozen other important social phenomena could be equally well established. In fine, has not the frequency of accident grown in countries that have no system of labor insurance as well? Let us look at the statistics of railway accidents in this country, for instance, where one out of each eleven trainmen is injured each year, and one out of each $r_{30}$ is killed. Above all things, let us be fair and consistent, and let us not deny the overworked workingman the same human right to an excusable degree of carelessness which even the men of leisure possess.

The assertion that compulsory labor insurance has not created gratitude toward the government and conciliation toward employers is to our view entirely beside the mark. Shorn of its oratorical flowers, it simply means that compulsory State insurance of labor has not sounded the death-knell to all other efforts of the wage workers toward their betterment. This, however, is not the proper function of labor insurance at all, no matter what the secret designs of a Bismarck may have been. That labor insurance might have such a result was certainly feared by the progressive German wage workers and their friends. Because of this fear the plan of labor insurance was [340] 
objected to by the German Social Democrats on one side and by advocates of trade-unionism, like L. Brentano, on the other. These fears have been shown to be unfounded. For that very reason the antagonism between the wage workers' political and economic organizations on one hand and labor insurance on the other has gradually vanished. German workingmen have long since found out, and the American workingmen may soon find out, that a legally enacted and controlled system of insurance against sickness, accident, invalidity, old age, and death, instead of competing with, actually supplements the work of their labor organizations. Schultze-Delitch's ideal of a trade-union as an organization for mutual charity has long since been thrown overboard. American as well as English unions sometimes still keep up some activity in that line, but they do it out of sheer necessity, as a workingman brought to destitution by an accident or disease may prove unsafe in his trade union-principles. It has been acknowledged by many practical employers, as well as the majority of American employees, that the trade-union is primarily a highly specialized machine for a very definite object-a machine for collective bargaining - a machine whose function it is to use all legitimate means to strike as good a bargain for its members as conditions will permit. Though as yet there is no concerted demand on the part of American-trade unionists for a system of compulsory State insurance, it can hardly be doubted that the plan would appeal to them if properly presented. It would greatly relieve the treasuries of those unions which have at present a system of sickness and accident benefits. With the transfer of the burden from the union to the State, the former would be better prepared to furnish the one kind of insurance that the unions are best able to grant-insurance against unemployment.

The various efforts to provide for some system of State insurance against unemployment have invariably failed, and this failure was in no sense accidental, but inherent in the very nature of the problem. Unemployment is rapidly becoming a more frequent cause of poverty than even sickness or accident. ${ }^{8}$ But a free supply of means of existence to a healthy worker would be detrimental to character. Besides, it would be perfectly idle to expect modern society to contri-

8 Prof. Farnam evidently forgets this break in the German system of insurance when he quotes statistics of poverty and charity as an evidence of the inefficiency of State insurance. [34 I] 
bute toward this support, when an army of unemployed is considered a necessary condition for the working out of "economic laws."

Nor could the ordinary unemployment be easily differentiated from voluntary unemployment, whether in its individual form of refusing anything less than the union wage or the social form of strikes. The basis of State insurance against unemployment must necessarily be assistance in case of absolute impossibility to obtain work for wages ever so small. The basis of trade-unionism is "No work for less than the standard wage." It is evident, therefore, that unless the State be ready to regulate wages it cannot conduct a system of unemployment insurance which would be satisfactory to the union worker. Assistance in case of unemployment, as out-of-work benefits as well as strike benefits, are the natural functions of the tradeunion. But even outside of this consideration the relegation of all other forms of insurance to the State would in no way relieve the unions from any interest in the matter. The benefits of labor insurance will not accrue to a perfectly passive class of wage-earners. As Mr. Pinkus says: "Regulation of wages ought to, and indeed may, include besides the means of support, also the insurance premium for sickness, accident, invalidity, old age and lack of employment." The tendency to discount the value of the insurance from the wages will have to be actively contested; the honest execution of any insurance law must be actively guarded by the trade-unions. We may add that an efficient system of labor insurance will never be legally enactedwill never grow and develop without the active influence of tradeunion votes. A short experience would easily convince the union worker that a well regulated system of compulsory State insurance of labor will prove of great assistance to the trade-unions in their struggle for the economic and social betterment of the American workingman.

Washington, D.C.

I. M RuBinow. 